[Technical Paper]

\title{
Relationship between Copper Patterns and Temperature Rise of Printed Circuit Board for Small Surface Mount Electronic Components in Terms of Constriction Thermal Resistance
}

\author{
Yoshinori Aruga*, Koichi Hirasawa*, Hirotoshi Aoki*, Tomoyuki Hatakeyama**, Shinji Nakagawa**, \\ and Masaru Ishizuka** \\ *KOA CORPORATION, 14016, Nakaminowa, Minowa-machi, Kamiina-gun, Nagano 399-4697, Japan \\ **Toyama Prefectural University, 5180, Kurokawa, Imizu-shi, Toyama 939-0398, Japan
}

(Received August 10, 2016; accepted January 30, 2017, published March 31, 2017)

\begin{abstract}
In recent years, the circuit (printed board) designers play an increasingly important role in the thermal design of electronic devices. Generally, small chip type components generate but a very low level of heat. Lately, however, the heat generation density of small chip type components is rising along with the downsizing of electronics. Small chip type components have no cooling devices, and heat dissipation from the components occurs mainly through the copper pattern on the board. Therefore, if the design of copper pattern on the board is inadequate, generated heat from the components cannot be dissipated, thus running a risk of excessive temperature rise.

This paper discusses the relationship between the mounting pad shape and the temperature rise of the board, which can be significant in the thermal management of small surface mount components. Using the concept of constriction thermal resistance, the temperature of the component can be estimated easily without taking complex copper patterns into consideration.
\end{abstract}

Keywords: Constriction Thermal Resistance, Chip Type Component, Chip Resistor, SMD, Thermal Management, Printed Circuit Board

\section{Introduction}

1.1 Temperature rise problem of small chip components in thermal design

Recently, the thermal design on the circuit board becomes more difficult with the miniaturization and high density of electronic devices. Among them, heat dissipation of small components is a problem. The components, such as power semiconductors that are primarily anticipated to produce much heat, are provided with heat dissipation measures such as dedicated heatsinks. Thus thermal control is relatively easy. With small chip components, such as surface mount type chip resistors (hereinafter referred to chip resistor), heat dissipation measures are often not adequately taken because they are used in large numbers on a circuit and each of them produces only a small amount of heat (a few hundred $\mathrm{mW}$ to several $\mathrm{W}$ ). However, even when the amount of heat is small, there are many cases where pattern design must be reviewed because of unexpected temperature rise during actual circuit operation due to the high density of heat flux from chip components. When using small chip components, the pattern design is important to achieve sufficient heat dissipation because the temperature rise of the component varies greatly with the heat dissipation condition of the surface-mounted pattern. However, the specific guidelines or design rules for that purpose are not always available. Designing the board pattern is part of the work for the circuit and board designers. And the circuit designers who mainly had to deal with electrical design in the past are now required to perform thermal design as well. However, thermal design has been done mainly by mechanical designers, and many circuit designers are not experts in thermal design. For this reason, establishing simpler and clearer method for pattern design is under urgent necessity. 


\subsection{Necessity of revising temperature reference to chip components}

For small size heat-generating components such as chip resistors, miniaturization of components is progressing while components are keeping the load power, and the heat density on the board rises rapidly. Under such circumstances, a problem arises when ambient temperature conventionally used as the reference temperature for determining the load power of the surface mount components. The chip resistor is taken as an example and is referred as follows. Since the resistor is a heat generating component, it is specified in the standard of IEC 60115 series[1] to reduce the load power when the ambient temperature to be operated is high. Specifically, based on a graph called a derating curve as shown in Fig. 1, when the ambient temperature is higher than the rated temperature, the load power to the resistor is reduced and the temperature rise of the resistor is suppressed. (The rated temperature in the figure is $70^{\circ} \mathrm{C}$ in many cases.) Such derating method is established on the premise that the temperature rise of the resistor is determined depending on the ambient temperature. The leaded type resistor has a large surface area and the proportion of heat dissipation due to radiation and convection is large, and that the temperature of the leaded type resistor depends on the ambient temperature. However, this is not applied to chip resistors. Even if the size of the chip resistor is large such as about $6.3 \mathrm{~mm} \times 3.2 \mathrm{~mm}$, its surface area is small, so the heat dissipation of the chip resistor by convection and radiation is small. Most of the heat flow first spreads into the board by thermal conduction and then is transferred to the ambient by convection and radiation through the board surface. Therefore, the temperature of the chip resistor largely depends on the thermal resistance and the temperature of the board which directly transfers the heat. The temperature of the chip resistor does not depend on the temperature of ambient which indirectly transfers the heat. As the countermeasure, there is a proposition to change the reference to the terminal part temperature (temperature at the connecting portion of board and component) that more reflects the component temperature.[2] In order to appropriately use the components based on the terminal part temperature, it is necessary to measure the terminal part temperature. The "terminal part" means a soldered portion between the component and the board as shown in Fig. 2. The terminal part is extremely small, and when measuring the temperature of this part, it is necessary to attach a very thin thermocouple to the solder fillet part as

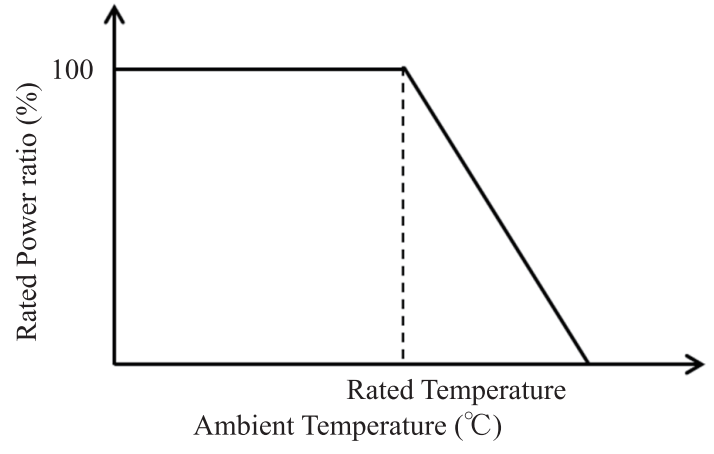

Fig. 1 Derating curve for the resistors.

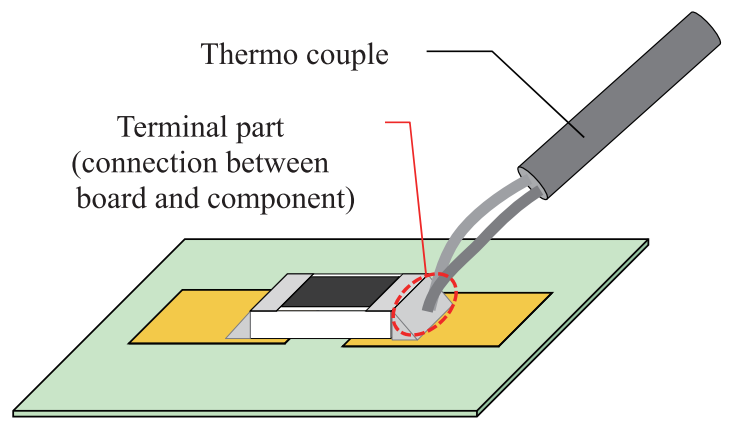

Fig. 2 Measuring method of terminal part temperature.

shown in Fig. 2. Details of the measurement method are described in Ref.[2] Since the temperature gradient at the fillet portion is small, the highest value of the mounting pad portion temperature can be used in simulation.

Normally, it is difficult to check the actual components temperature at the early stage of product and board design. Therefore, in order to appropriately use components based on the terminal part temperature, it is necessary to estimate and control the terminal part temperature beforehand.

\subsection{Existing thermal design method and the aim of this study}

Thus far, many studies have been done on the thermal design of electronic equipment. For example, temperature rise and heat diffusion around large components on the board[3] and analysis methods taking convection inside enclosures into consideration[4-6] have been proposed. Also, with respect to components, studies are being carried out on the internal modeling of MPU (Micro Processing Unit).[7] However, there is not much research in this field on small ( $5 \mathrm{~mm}$ or smaller) chip components.

Although the use of simulation is effective for thermal design, it is difficult to estimate the temperature of each chip component at the stage of pattern design. In order to carry out the thermal fluid simulation to estimate the board temperature, it is necessary to input the copper pat- 
tern, arrangement of heat generating component, and structure of the enclosure in detail. However, usually at the stage of pattern design, such information is often undefined and cannot be prepared. Currently, detailed thermal fluid simulation is often used for confirmation in the later stage of the design.

Based on the above situation, this paper discusses the relation between the mounting pad dimensions and temperature rise of single chip components using simulation as a basic investigation to establish a method for mounting pad design for small chip components. Additionally, the observed mode of heat transfer through the component, mounting pad, and board will be discussed. And a technique for separating the ranges of the phenomena also will be discussed.

\section{The Thermal Network Model of the Chip Compo- nent Mounted on the Board}

The temperature rise when a small chip heat-generating component is mounted on the board is described using its mode of heat dissipation. An image of the temperature distribution on the board and the thermal network is as shown in Fig. 3. Let us define the temperature rise in the
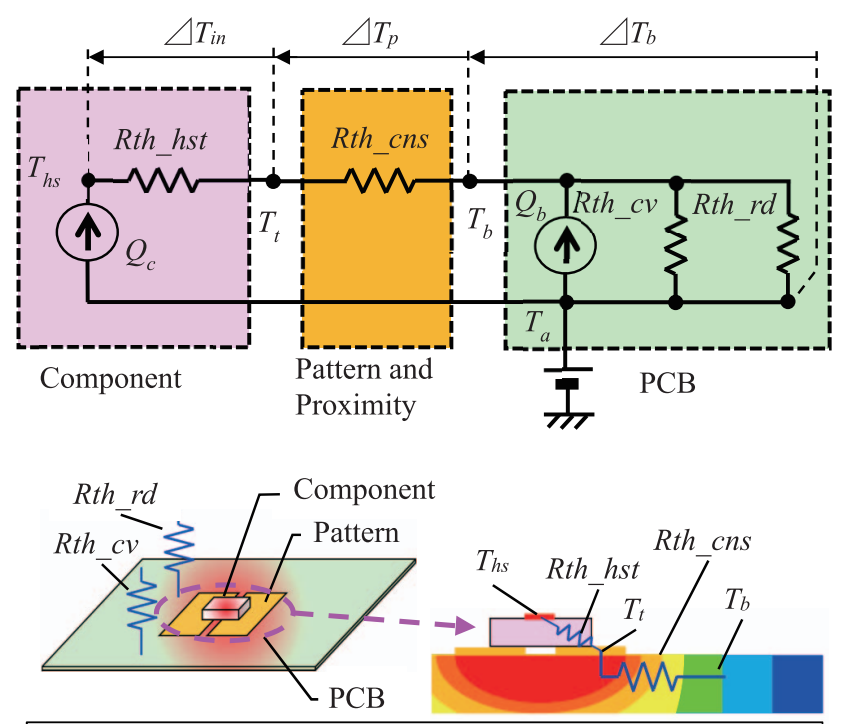

$Q_{c}$ : Component heat generation

$Q_{b}$ : Heat generation on the board except for $Q_{c}$

$T_{h s}$ : Component hot-spot temperature

$T_{t}$ : Component terminal part temperature

$T_{b}$ : Board temperature

$T_{a}$ : Ambient temperature

Rth_hst: Component thermal resistance( Hot-spot to terminal part)

Rth cns: PCB pattern constriction thermal resistance

Rth_cv: Thermal resistance of convection cooling from the board

Rth_rd: Thermal resistance of radiation cooling from the board

Fig. 3 The temperature distribution on the PCB and expression by thermal network. proximity of the component as the following Eq. (1) - (3).

$$
\begin{aligned}
& \Delta T_{i n}=T_{h s}-T_{t} \\
& \Delta T_{p}=T_{t}-T_{b} \\
& \Delta T_{b}=T_{b}-T_{a}
\end{aligned}
$$

where $T_{h s}$ : Component hot-spot temperature, $T_{t}$ : Component terminal part temperature, $T_{b}$ : Board temperature, $T_{a}$ : Ambient temperature.

The thermal resistance of each part is expressed by the following equations.

$$
\begin{aligned}
& \text { Rth_hst }=\Delta T_{i n} / Q_{c} \\
& R t h \_c n s=\Delta T_{p} / Q_{c} \\
& \frac{1}{R t h \_c v}+\frac{1}{R t h \_r d}=\frac{Q_{c}+Q_{b}}{\Delta T_{b}}
\end{aligned}
$$

$\Delta T_{\text {in }}$ is the internal temperature rise of the component which is determined by the heat generation $Q_{c}$ and internal thermal resistance Rth_hst of the component. Small chip components have small surface area, so heat dissipation due to convection and radiation is small, and it can be considered that almost all of the heat is transferred by conduction. Therefore, Rth_hst is determined by the shape of the components and the thermal conductivity of the material.

Figure 4 shows an image of the heat transfer mode of the board on which the chip component is mounted. The process of heat transfer can roughly be divided into two parts by the heat transfer mode. The first is a process in which heat spreads into the board mainly by thermal conduction in a narrow area proximity of the component, and the temperature rise in that range is defined as $\Delta T_{p}$. The

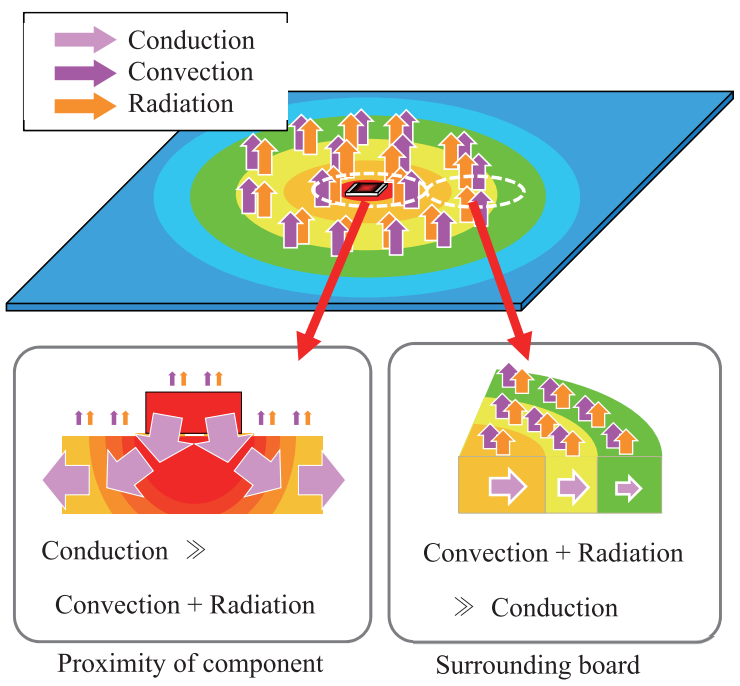

Fig. 4 Heat transfer mode of the board on which the chip component is mounted. 
thermal resistance Rth_cns determines $\Delta T_{p}$, and it mainly depends on the mounting pad shape of the component and the thermal conductivity of the board. Rth_cns includes the spread thermal resistance caused by the rapid spread of heat flux from the mounting pad to the board when the heat is transferred from the component terminal part to the board via mounting pad. The authors call this phenomenon "constriction thermal resistance" in view of the similarity to constriction resistance which is a phenomenon resulting from potential difference caused by concentration of current densities. [8, 9]

The second is a process in which heat transfers from the board surface to the ambient by convection and radiation in a large area of the board, and the temperature rise in that range is defined as $\Delta T_{b}$. The thermal resistances Rth_cv and Rth $r d$ that determine $\Delta T_{b}$ depend on the shape of the board and its surroundings, the wind speed, and the emissivity of the surface.

It is possible to separate the temperature rise $\Delta T_{p}$ in the proximity of the component from the board temperature $T_{b}$ by using proposed thermal network model. The $\Delta T_{p}$ largely depends on the shape of the mounting pad. Conversely, it becomes possible to control the terminal part temperature of the component $T_{t}\left(T_{t}=T_{b}+\Delta T_{p}\right)$ by adjusting the pad shape and setting Rth_cns to an appropriate value.

For this idea, it is important to determine the position indicating the temperature $T_{b}$ (hereinafter called component boundary) which is the boundary separating $\Delta T_{p}$ and $T_{b}$. The boundary determination method suitable for the proposed thermal network model is discussed below.

\section{Modeling and Simulation Condition}

\subsection{Simulation model}

We carried out a simulation based on the preceding dis-

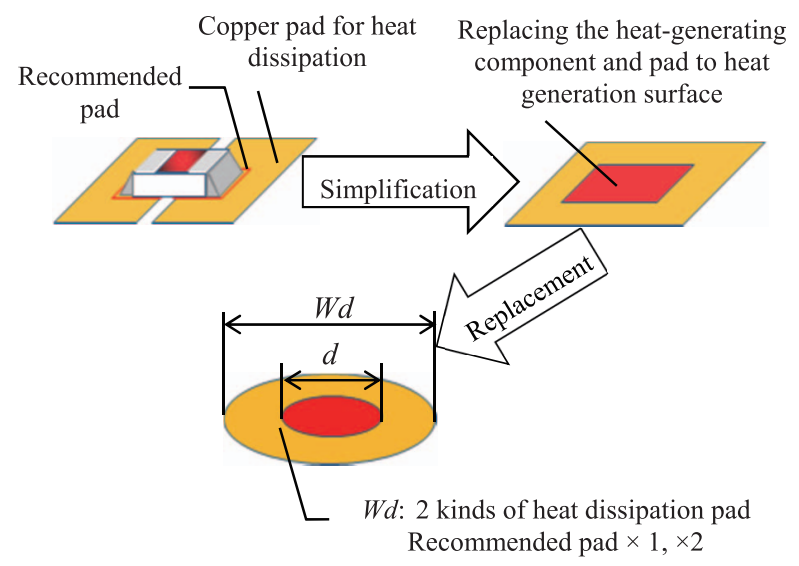

Fig. 5 Modeling of component and adjacent pattern. cussion on the temperature rise of the components mounted on the board. FEM (Finite Element Method) was used for discretization of model shape and Femtet ${ }^{\circledR} 2015$ was used for simulation. Our investigation was based on normal usage conditions, assuming a heat generating component mounted on a horizontally set glass epoxy board with single-sided copper foil. In this analysis, a disc-shaped model was used as a target board in consideration of a general trend. And, accordingly, the component and copper pad were simplified as shown in Fig. 5. The Rth_hst of the component, which varies widely with the internal structure, was not dealt with in this verification. It was instead substituted by a heat source of heat influx from the connection of the component.

The diameter $d$ of the heat generating part was set as $d=$ $1.5 \mathrm{~mm}$ assuming a chip resistor of $1.6 \mathrm{~mm} \times 0.8 \mathrm{~mm}$ size $(1.6 \times 0.8 \mathrm{~mm}$ size $)$ and as $d=2.0 \mathrm{~mm}$ assuming a chip resistor of $2.0 \mathrm{~mm} \times 1.2 \mathrm{~mm}$ size $(2.0 \times 1.2 \mathrm{~mm}$ size $)$. And the amount of heat generation $Q_{c}$ was set at $0.25 \mathrm{~W}$. Also, heat dissipation pad $W d$ was set to be equal to $d$ and 2 times $d$.

In the actual analysis, the sectional shape of Fig. 6 was treated as a cylindrical coordinate system centered on the symmetry axis. Therefore, the heat conduction in the solid was given by the differential equation of the Eq. (7) and (8). Eq. (7) describes heat transfer in the radial direction, and Eq. (8) describes heat transfer in the thickness direction. Mesh division is set to $0.05 \mathrm{~mm}$ in the proximity of the center part and around $0.1 \mathrm{~mm}$ in the peripheral part.

$$
\begin{aligned}
& \mathrm{d} T=-\frac{Q_{r}}{2 \pi \lambda} \frac{\mathrm{d} r}{r},\left(Q_{r}=2 \pi r q_{r}\right) \\
& q_{z}=-\lambda \frac{\mathrm{d} T}{\mathrm{~d} z}
\end{aligned}
$$

where $T$ : Temperature, $r$ : Radial position, $Q_{r}$ : Amount of heat flow passing through the cylindrical surface, $\lambda$ : Ther-

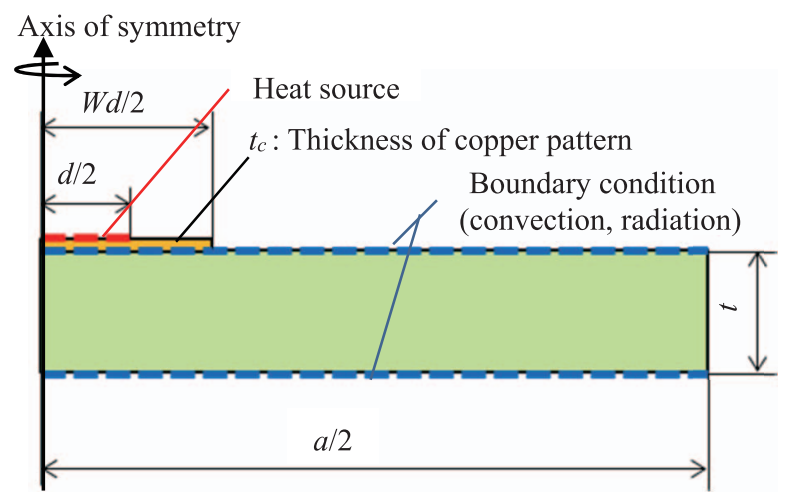

Fig. 6 Simulation model. 
Table 1 Dimensions of board and copper pad.

\begin{tabular}{c|c|c|c|c}
\hline$d(\mathrm{~mm})$ & $\begin{array}{c}W d \\
(\mathrm{~mm})\end{array}$ & $\begin{array}{c}a \\
(\mathrm{~mm})\end{array}$ & $\begin{array}{c}t \\
(\mathrm{~mm})\end{array}$ & $\begin{array}{c}t_{c} \\
(\mathrm{~mm})\end{array}$ \\
\hline $\begin{array}{c}1.5 \\
(1.6 \times 0.8 \mathrm{~mm} \\
\text { equivalent })\end{array}$ & $1.5,3.0$ & & & \\
\hline 2 & & $\begin{array}{c}70, \\
2.00,\end{array}$ & 1.6 & 0.035 \\
$\begin{array}{c}(2.0 \times 1.2 \mathrm{~mm} \\
\text { equivalent })\end{array}$ & $2.0,4.0$ & 150 & & \\
\hline
\end{tabular}

Table 2 Thermal conductivity of materials.

\begin{tabular}{c|c}
\hline Material & Thermal conductivity $\left[\mathrm{W} \mathrm{m}^{-1} \mathrm{~K}^{-1}\right]$ \\
\hline Glass epoxy & 0.6 \\
\hline Copper & 397 \\
\hline
\end{tabular}

mal conductivity, $q_{z}$ : Heat flow of $z$ direction, $q_{r}$ : Heat flow of radial direction, $z$ : Position in the thickness direction.

Heat transfer of convection and radiation were set as the boundary conditions on the board surface (top surface and bottom surface). For the heat transfer by convection to the ambient air, $h$ given by Eq. (9) was used. Equation (9) is shown in Ref.[10] and is often used in calculations of practical thermal design.

$$
h=k \cdot 2.51\left\{\left(T-T_{a}\right) / L\right\}^{0.25}
$$

where $T$ shows the temperature at each point, $L=a \times$ $10^{-3} \mathrm{~m}$, constant of shape $k=0.54$ (plate placed horizontally with hot side top), 0.27 (plate placed horizontally with hot side bottom).

As shown in Eq. (9), constant values are given in the model, $L$ for the shape and $k$ for the installation state. Actual $h$ is a different value for each point depending on the temperature $T$.

Heat transfer by radiation from the surface of the board to the ambient air is given by the Eq. (10)

$$
Q_{\text {rad }}=\varepsilon \sigma\left\{(T+273.15)^{4}-\left(T_{a}+273.15\right)^{4}\right\}
$$

where $Q_{\text {rad }}$ : heat dissipation by radiation, $\sigma$ : StefanBoltzmann constant, $\varepsilon$ : emissivity of board surface.

It is to be noted that the boundary conditions of the copper pad, as shown in the Fig. 6, are set for the interface between the resin and the copper pad. This is done for the simplification of the model. These boundary conditions should normally be set for the copper pad surface. But under the conditions for this simulation, the temperature difference between the surface side and the resin side of the copper pad was $0.1^{\circ} \mathrm{C}$ or less, which did not affect the

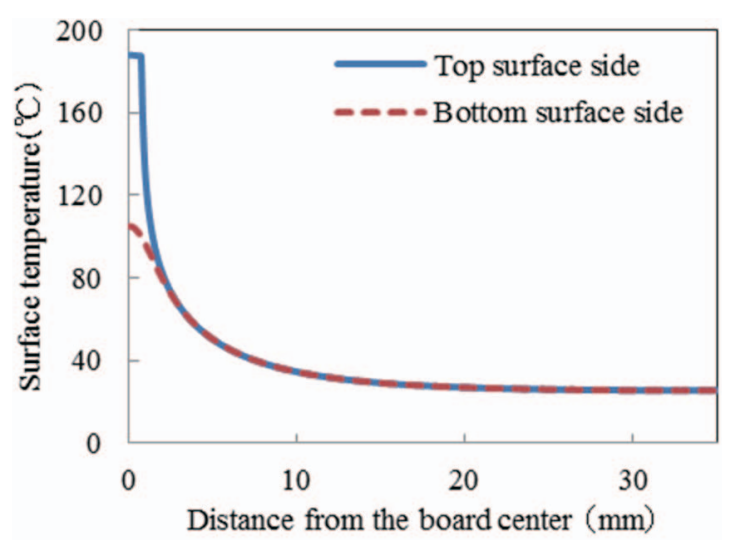

(a) Distribution of surface temperature

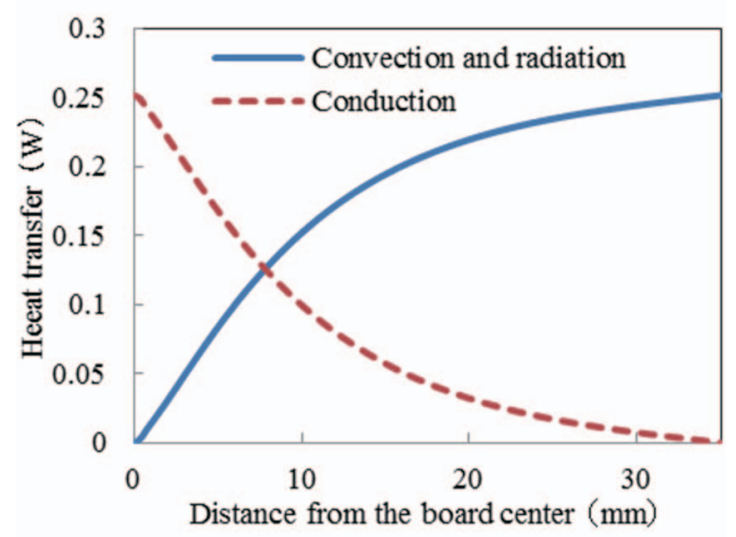

(b) Distribution of heat transfer

Fig. 7 Distribution of temperature and heat transfer $(d=1.5$, $W d=1.5, a=70)$.

analysis results.

In this analysis, thermal fluid analysis is not used for convection, so the influence of heat transfer may include some error. However, in the proximity of the component, most of the heat is transferred by thermal conduction, so the influence of the above error is small for the main parameters such as Rth_cns.

\subsection{Simulation condition}

The dimensions of each component and its physical properties as the conditions for simulation are shown in Table 1, and the thermal conductivity of materials in Table 2. Other conditions employed are as shown below:

Component heat generation amount $Q_{c}=0.25 \mathrm{~W}$, emissivity of board surface $\varepsilon=0.9$, and ambient temperature $T_{a}=25^{\circ} \mathrm{C}$.

\section{Results and Discussion}

\subsection{Total extent of temperature distribution and} state of heat dissipation

The simulation results of temperature distribution under the conditions of $a=70 \mathrm{~mm}, d=1.5 \mathrm{~mm}$ and $W d=1.5 \mathrm{~mm}$ are shown in Fig. 7(a). From the graph, it can be observed 
Table 3 Heat transfer from the surface.

\begin{tabular}{c|c|c|c|c}
\hline \multirow{2}{*}{} & \multicolumn{2}{|c|}{$\begin{array}{r}a=1.5, W=1.5, \\
a=70\end{array}$} & \multicolumn{2}{c}{$\begin{array}{r}d .5, W d=1.5, \\
a=150\end{array}$} \\
\cline { 2 - 5 } & Convection & Radiation & Convection & Radiation \\
\hline $\begin{array}{c}\text { Top } \\
\text { side } \\
(\mathrm{W})\end{array}$ & 0.063 & 0.081 & 0.055 & 0.088 \\
\hline $\begin{array}{c}\text { Bottom } \\
\text { side } \\
(\mathrm{W})\end{array}$ & 0.03 & 0.077 & 0.026 & 0.083 \\
\hline $\begin{array}{c}\text { Total } \\
(\mathrm{W})\end{array}$ & 0.093 & 0.159 & 0.082 & 0.171 \\
\hline$\%$ & 36.93 & 63.07 & 32.26 & 67.74 \\
\hline
\end{tabular}

that the board temperature is basically equal to the ambient temperature at points $25 \mathrm{~mm}$ or more away from the center of the board. Figure 7(b) shows the distribution of heat transfer by convection and radiation. From this graph of heat transfer by convection and radiation, it is evident that nearly $95 \%$ of the heat is released by convection and radiation at points $25 \mathrm{~mm}$ away from the board center. (This tendency holds true irrespective of the dimension of $d$, $W d$ and $a$.) This means that the component mounted with a spacing of more than $25 \mathrm{~mm}$ from adjacent ones may not be thermally affected by them. This is an important piece of information in controlling the temperature rise of the component.

As shown in Table 3, the heat transfer by convection and radiation varies slightly with the external diameter of the board, but the ratio of one by convection is around $35 \%$, whereas that of one by radiation is around $65 \%$. It indicates that the heat dissipation by convection is less than that by radiation. In this study, heat transfer assumed was one by natural convection, and therefore under forced convection, the percentage of heat transfer by convection may increase, thus influencing the board temperature. Also, with small-size sealed devices which are much less affected by heat transfer by convection, the percentage of heat dissipation by radiation is expected to be much higher.

\subsection{Disscusion about the temperature distribution} proximity of the heat-generating part and determining the method of the component boundary

Figure 8 shows isothermal diagrams under respective condition. The isothermal lines for the respective conditions run perpendicularly to the $\mathrm{y}$ axis near the heat source, but they change into the direction perpendicular to the $\mathrm{x}$ axis as the temperature declines. The heat flux trans-
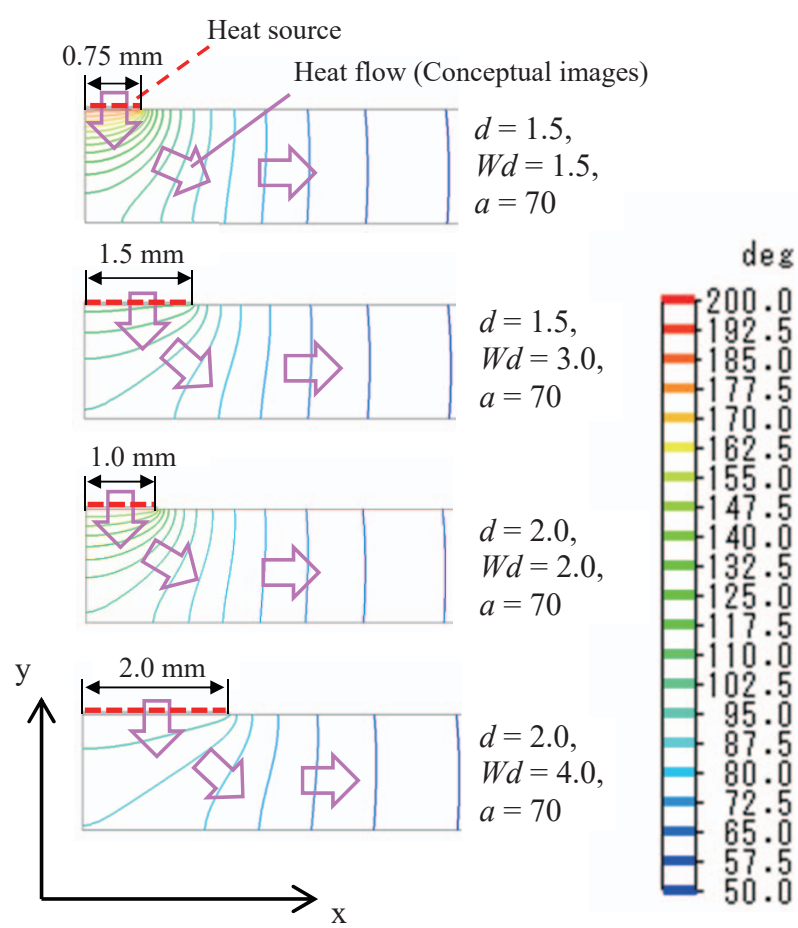

Fig. 8 Isotherms of temperature distribution.

ferring through the board flows in a direction perpendicular to the isothermal lines as indicated by the arrows. It can be observed therefore that the heat flux flows in the $-y$ direction at the heat source and gradually changes its direction into the $+\mathrm{x}$ direction. The heat flux inside the board varies greatly with the size of the pad. For example, with a small pad of $d=1.5 \mathrm{~mm}, W d=1.5 \mathrm{~mm}$, the heat flux changes its direction near the heat source, while causing rapid temperature changes, but with a large pad of $d=2.0$ $\mathrm{mm}, W d=4.0 \mathrm{~mm}$, the heat flux flows through the board with small temperature differences. We call this conspicuous thermal resistance (temperature difference) that occurs with small patterns "constriction thermal resistance".

The constriction thermal resistance is a phenomenon that occurs in the transition stage where the heat flux changes its direction from $-\mathrm{y}$ to $+\mathrm{x}$ direction. Therefore, it would be appropriate to evaluate the thermal resistance in this range as the Rth_cns. As shown in Fig. 7(a), the temperatures of the top surface and the bottom surface of the board are equal to each other at a point short away from the heat generating portion. At this point, the heat flux shows the $+\mathrm{x}$ direction and the transition completes. To be more precise, it is determined that the point where the temperature difference between the top and bottom surface of the board as shown in Fig. 7(a) becomes smaller than $1 \%$ of the maximum value of the board temperature rise as the component boundary. 


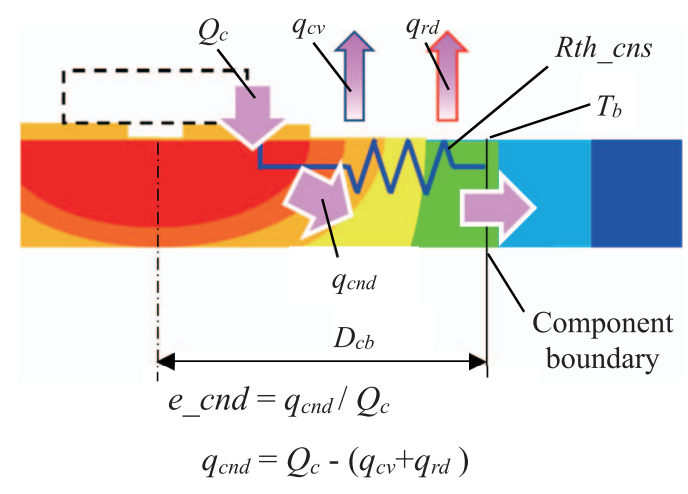

$D_{c b}$ : Distance between the board center and component boundary $q_{c v}$ : Amount of heat convection in $D_{c b}$ section

$q_{r d}$ : Amount of heat radiation in $D_{c b}$ section

$q_{c n d}$ : Amount of heat conduction in $D_{c b}$ section

Fig. 9 Definition of $D_{c b}$ and $e_{-} c n d$.

The distance between the center of the board and the component boundary is defined as $D_{c b}$. Furthermore, $e_{-}$cnd is defined as an index showing the ratio of heat transfer due to thermal conduction from the heat source to the component boundary. $e_{-}$cnd is expressed by Eq. (11) and (12).

$$
\begin{aligned}
& e \_c n d=q_{c n d} / Q_{c} \\
& q_{c n d}=Q_{c}-\left(q_{c v}+q_{r d}\right)
\end{aligned}
$$

The definition of $D_{c b}$ and $e_{-} c n d$ are shown in Fig. 9 .

Table 4 shows $D_{c b}$, Rth_cns, and $e_{-} c n d$ (at the component boundary) under the respective conditions. Among the conditions, it can be seen that $a$ (diameter of the board) has little influence on Rth_cns.

Figure 10 shows the temperature distribution (on board top surface) and the value of $e_{-}$cnd in the section from the board center to the component boundary. As shown in Fig. 10 , when $W d$ is about double the size of the heat source diameter $d$, the temperature within the pad (range from 0 to $W d$ ) is almost constant. The graph also shows that nearly $80 \%$ of the heat flux is transferred by thermal conduction within the $D_{c b}$ section.

The relation between the diameter of heat dissipation pad Wd and Rth_cns is shown in Fig. 11. It shows that Rth_ cns decreases with the increase in Wd. Also, Rth_cns is proportional to the minus 1st power of $W d$ and greatly influences the temperature drop near the component. It is important to pay attention to the $e_{-} c n d$ to further investigate the relationship between the heat dissipation pad and Rth_cns.

In any conditions, the value of $e_{-} c n d$ is around $80 \%$, indicating that thermal conduction is the dominant factor in heat transfer. The thermal conduction through the board

\begin{tabular}{|c|c|c|c|c|c|c|}
\hline$d(\mathrm{~mm})$ & \multicolumn{6}{|c|}{1.5} \\
\hline$W d(\mathrm{~mm})$ & \multicolumn{3}{|c|}{1.5} & \multicolumn{3}{|c|}{3} \\
\hline$a(\mathrm{~mm})$ & 70 & 100 & 150 & 70 & 100 & 150 \\
\hline $\begin{array}{c}D_{c b} \\
(\mathrm{~mm})\end{array}$ & 2.5 & 2.5 & 2.5 & 3.3 & 3.3 & 3.3 \\
\hline $\begin{array}{c}\text { Rth_cns } \\
(\mathrm{K} / \mathrm{W})\end{array}$ & 461 & 462 & 463 & 227 & 228 & 228 \\
\hline $\begin{array}{c}\text { e_cnd } \\
\text { (at the component } \\
\text { boundary) } \\
(\mathrm{U})\end{array}$ & 0.84 & 0.85 & 0.85 & 0.80 & 0.80 & 0.81 \\
\hline$d(\mathrm{~mm})$ & \multicolumn{6}{|c|}{2} \\
\hline$W d(\mathrm{~mm})$ & \multicolumn{3}{|c|}{2} & \multicolumn{3}{|c|}{4} \\
\hline$a(\mathrm{~mm})$ & 70 & 100 & 150 & 70 & 100 & 150 \\
\hline $\begin{array}{c}D_{c b} \\
(\mathrm{~mm})\end{array}$ & 2.8 & 2.8 & 2.8 & 3.8 & 3.9 & 3.9 \\
\hline $\begin{array}{c}\text { Rth_cns } \\
(\mathrm{K} / \mathrm{W})\end{array}$ & 341 & 342 & 342 & 169 & 173 & 173 \\
\hline $\begin{array}{c}\text { e_cnd } \\
\text { (at the component } \\
\text { boundary) } \\
\text { (U) }\end{array}$ & 0.82 & 0.83 & 0.83 & 0.77 & 0.77 & 0.77 \\
\hline
\end{tabular}

Table 4 Result of $D_{c b}$, Rth_cns and $e_{-} c n d$.

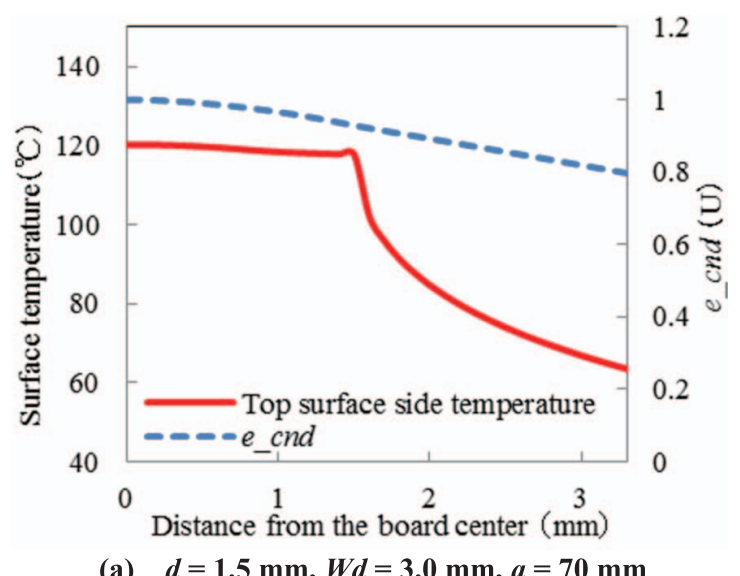

(a) $d=1.5 \mathrm{~mm}, W d=3.0 \mathrm{~mm}, a=70 \mathrm{~mm}$

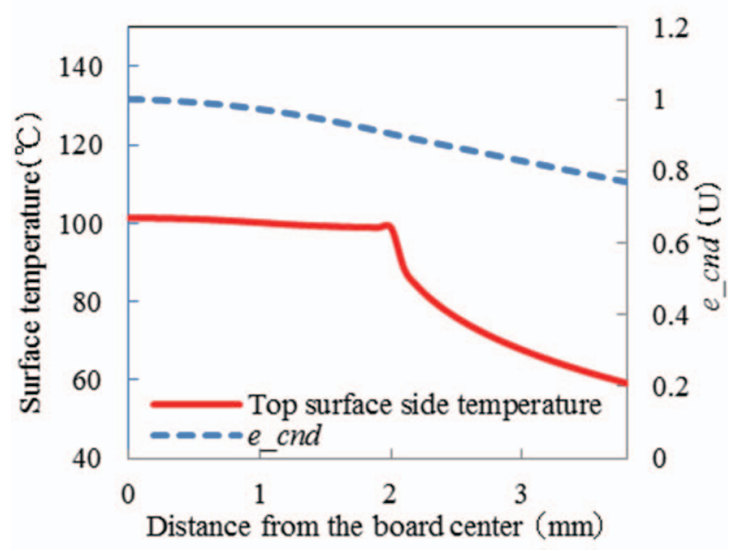

(b) $d=2.0 \mathrm{~mm}, W d=4.0 \mathrm{~mm}, a=70 \mathrm{~mm}$

Fig. 10 Distribution of surface temperature and $e_{-} c n d$. 


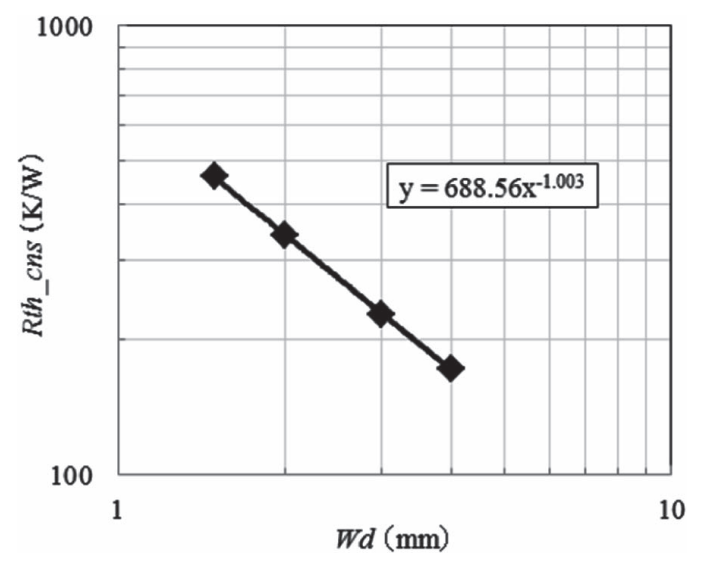

Fig. 11 Relation between $W d$ and Rth_cns $(a=70)$.

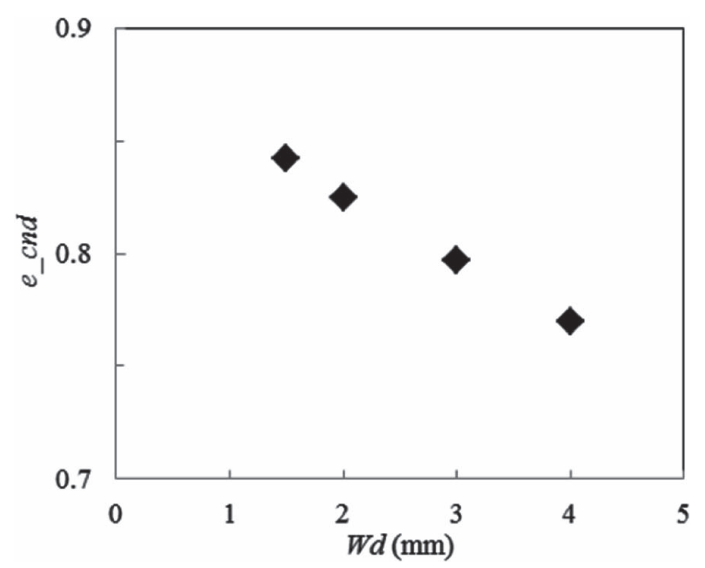

Fig. 12 Relation between $W d$ and $e_{-} c n d(a=70)$.

is affected not only by copper pattern but also by the thermal conductivity of board material. Therefore, it is supposed that the thermal conductivity of the board material greatly affects $R t h \_c n s$.

Figure 12 shows the relation between $W d$ and $e_{-} c n d$ when $\mathrm{a}=70 \mathrm{~mm}$. $e_{-} c n d$ decreases when $W d$ increases. This is due to the increase in heat dissipation by both convection and radiation.

As described above, the $Q_{c}$ (heat generation of the component) is fixed at $0.25 \mathrm{~W}$ in this study. The amount of heat transfer by radiation and convection is nonlinear with temperature, and $e_{-} c n d$ tends to decrease when $Q_{c}$ is large. Considering the actual use conditions, heat generation value of $0.25 \mathrm{~W}$ is large in the case $1.6 \times 0.8 \mathrm{~mm}$ or $2.0 \times$ $1.2 \mathrm{~mm}$ size chip components are assumed in this study. Therefore, actual $e_{-} c n d$ is expected to be higher than that of this study under many actual conditions. When $Q_{c}$ is extremely small, $e_{-}$cnd is approximately 1.0. The thermal resistance in that case can be approximated as Rth_cns / e_cnd.

Since this paper mainly discusses the proposal of the thermal network model and the method of determining the component boundary, the conditions of the board and the pad are limited. In Ref.[11] We have discussed using the method proposed in this paper to study the influence of the board thickness, thermal conductivity of the board material, and wider range of $W d$. It is shown that Rth_cns can be easily estimated from the thermal conductivity of the board and the dimension of $W d$ under the condition that heat transfer is done mainly by thermal conduction.

\section{Conclusion}

Our findings in this study are as follows:

- The state of heat dissipation when a small component is mounted on the board is represented by a thermal network model. It is possible to separate the temperature rise $\Delta T_{p}$ in the proximity of the component from the board temperature $T_{b}$ by using the thermal network model.

- A method for defining the component boundary (boundary between $\Delta T_{p}$ and the board temperature $T_{b}$ ), which would be necessary in applying the thermal network model, is proposed. That is, the component boundary is determined as the point where the temperature of the top surface and that of the bottom surface of the board become equal, from the result of temperature distribution simulation on the board.

- Within the range of constriction thermal resistance, approximately $80 \%$ of the inflow heat flux is transferred by thermal conduction, and it is assumed that it is under a significant influence of the thermal conductivity of the board material.

- The Rth_cns (constriction thermal resistance) depends more on the $W d$ (pad diameter) than the heat source $d$. And it is proportional to the minus 1st power of $W d$ as determined in our study.

From this study, we could gain the basic understandings necessary for estimating temperature rises when a small component is mounted on the board.

\section{Nomenclature}

$a$ : Diameter of board (mm)

$d$ : Diameter of heat source $(\mathrm{mm})$

$D_{c b}$ : Distance between the board center and component boundary (mm)

e_cnd: Ratio of heat transfer by thermal conduction to total heat dissipation in $\mathrm{D}_{\mathrm{cb}}$ section $\left(=q_{c n d} / Q_{c}\right)$

$h$ : Heat transfer coefficient $\left(\mathrm{W} / \mathrm{m}^{2} / \mathrm{K}\right)$

$k$ : Constant by shape

$L$ : Characteristic length (m) 
$Q_{b}$ : Heat generation on the board except for $Q_{c}(\mathrm{~W})$

$Q_{c}$ : Component heat generation (W)

$q_{c n d}$ : Amount of thermal conduction in $D_{c b}$ section $\left\{=Q_{c}-\right.$ $\left.\left(q_{c v}+q_{r d}\right)\right\}$ (W)

$q_{c v}$ : Amount of heat convection in $D_{c b}$ section (W)

$q_{r d}$ : Amount of heat radiation in $D_{c b}$ section (W)

Rth_cns: PCB pattern constriction thermal resistance $(\mathrm{K} / \mathrm{W})$

Rth_cv: Thermal resistance of convection cooling from the board $(\mathrm{K} / \mathrm{W})$

Rth_hst: Component thermal resistance (Hot-spot to terminal part) (K/W)

Rth_rd: Thermal resistance of radiation cooling from the board $(\mathrm{K} / \mathrm{W})$

$T$ : Temperature $\left({ }^{\circ} \mathrm{C}\right)$

$T_{a}$ : Ambient temperature $\left({ }^{\circ} \mathrm{C}\right)$

$T_{b}$ : Board temperature $\left({ }^{\circ} \mathrm{C}\right)$

$T_{h s}$ : Component hot-spot temperature $\left({ }^{\circ} \mathrm{C}\right)$

$T_{t}$ : Component terminal part temperature $\left({ }^{\circ} \mathrm{C}\right)$

$\Delta T_{i n}$ : Internal temperature rise of component $\left(T_{h s}-T_{t}\right)$

$\Delta T_{p}$ : Proximity temperature rise of component $\left(T_{t}-T_{b}\right)$

$\Delta T_{b}$ : Board temperature rise $\left(T_{b}-T_{a}\right)$

$W d$ : Diameter of heat dissipation pad (mm)

$\lambda$ : Thermal conductivity $(\mathrm{W} / \mathrm{m} / \mathrm{K})$

$\varepsilon$ : emissivity of board surface

$\sigma:$ Stefan-Boltzmann constant

\section{References}

[1] International Electrotechnical Commission, IEC60115-1:2008, Fixed resistors for use in electronic equipment - Part 1: Generic specification.

[2] Technical Standardization Committee, Technical Standardization Working Group on Passive Components, "Study for the derating curve of fixed surface mount resistors," Japan Electronics and Information Technology Industries Association, 2014, JEITA RCR-2114 (in Japanese).

[3] M. Ishizuka, "Netsu sekkei gijutsu kaiseki hand book (Thermal design technology and analysis hand book)," pp. 400-403, Mimatsu Co. ltd, 2008.

[4] W. Nakayama, R. Matsuki, Y. Hacho, and K. Yajima, "A New Role of CFD Simulation in Thermal Design of Compact Electronic Equipment: Application of the Build-up Approach to Thermal Analysis of a Benchmark Model," Journal of Electronic Packaging, Vol. 126, pp. 441-448, 2004.

[5] H. Yoshino, X. Zhang, and M. Fujii, "Numerical Simulations for Conjugate Heat Transfer from Heat Sources Mounted on a Conductive Wall," 15th Computational Mechanics Division Conference, 2002.

[6] H. Yoshino, X. Zhang, and M. Fujii, "Conjugate Heat Transfer from Heat Sources Mounted on a Conductive Wall," 39th National Heat Transfer Symposium of Japan, 2002.

[7] K. Nishi, T. Hatakeyama, S. Nakagawa, and M. Ishizuka, "Transient Heat Transfer of the Microprocessor System Investigation Regarding Natural Convection with Slate Style Chassis," Transactions of The Japan Institute of Electronics Packaging, Vol. 6, No. 1, 2013.

[8] K. Hirasawa, Y. Aruga, Y. Ohhashi, and T. Tomimura, "Study on error factor in temperature measurement of resin printed circuit board by thermocouples and its reduction method," 4th World Conference on Applied Sciences Engineering \& Technology, pp. 103-107, 2015.10.24-26.

[9] Y. Aruga, K. Hirasawa, Y. Ohhashi, N. Kunimine, and T. Tomimura, "Suggestions for Improving the Accuracy of the Temperature Measurement of Small Components by Thermocouples -On the Mounting Method Considering the Thermal Constriction Resistance and the Error-compensation by the Thermal Network-," 20th Symposium on Microjoining and Assembly Technology in Electronics, Vol. 20, pp. 187-192, 2014.2.3-4.

[10] N. Kunimine, "Erekutoronikusu no tame no netsu sekkei kanzen nyuumon (Perfect beginning guide of thermal design for electronics)," NIKKAN KOGYO SHIMBUN, LTD., 1997.

[11] Y. Aruga, K. Hirasawa, H. Aoki, T. Hatakeyama, S. Nakagawa, and M. Ishizuka, "A Study on Mounting Pad Shape and Thermal Resistance for Small Surface Mount Devices," IEEE CPMT Symposium Japan 2016, pp. 53-56, 2016.11.7-9. 


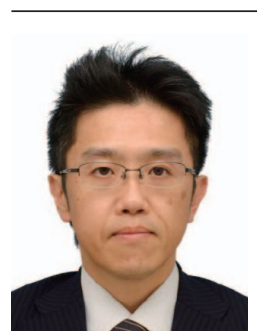

Yoshinori Aruga received the B.E. degree in 1998 from Kyushu Institute of Technology. He joined KOA Corporation and is engaged in technical support services to customers. He is also specialized in various measurement and simulation of the characteristics of resistors.

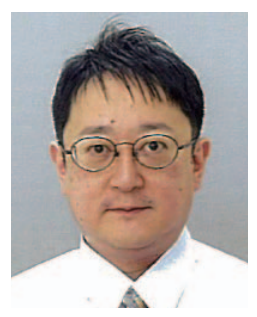

Koichi Hirasawa received the B.E. degree in 1987, M.E. degree in 1990 from Science University of Tokyo. He has worked as engineer in the Japan Meteorological Agency and as an electronic device designer in an electronics manufacturer. Now he works for KOA Corporation in the research and development division.

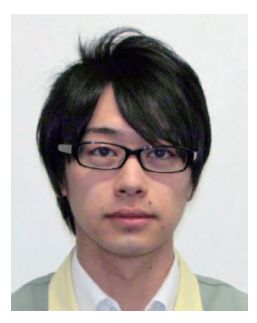

Hirotoshi Aoki received the B.E. degree in 2011 from Toyama University. He joined KOA Corporation and engaged in development of resistors. Currently, he is working on simulation and analysis.

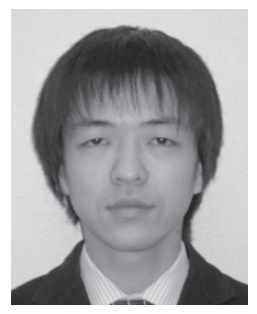

Tomoyuki Hatakeyama received the B.E. degree in 2003, M.E. degree in 2005 and the Ph.D. degree in 2008, all from Tokyo Institute of Technology in Japan. He is an assistant professor of Mechanical Systems Engineering at Toyama Prefectural University.

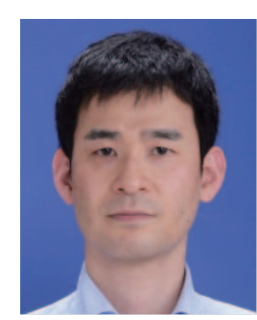

Shinji Nakagawa received the B.E. degree in 1993, M.E. degree in 1995 and the Ph.D. degree in 1999, all from Doshisha University in Japan. From 1999 to 2001, he studied turbulent flow at the University of Illinois. From 2001 to 2003, he was an assistant professor of Mechanical Systems Engineering at Aoyama Gakuin University. He was a lecturer from 2003 to 2008 , an associate professor from 2009 to 2015 , and is currently a professor of Mechanical Systems Engineering at Toyama Prefectural University, Japan.

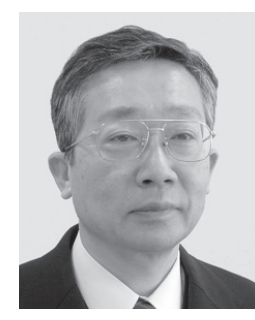

Masaru Ishizuka received the B.S. degree in 1975, M.S. degree in 1977 and the Ph.D. degree in 1981, all from the University of Tokyo in Japan. From 1981 to 2000, he worked for Toshiba Corporation, Kawasaki Japan, where he had been engaged in the research and development of the cooling technology of electronic equipment. From 2000 to 2003, he was an associate professor and, from 2003 to 2013, a professor of Mechanical Systems Engineering at Toyama Prefectural University, Japan. He is currently a president of Toyama Prefectural University. He is a Fellow of ASME and JSME, was the general chair of ICEP2014 in Toyama. 